\title{
Armillifer-Infected Snakes Sold at Congolese Bushmeat Markets Represent an Emerging Zoonotic Threat
}

\author{
Richard Hardi, ${ }^{1}$ Gergely Babocsay, ${ }^{2}$ Dennis Tappe, ${ }^{3}$ Mihály Sulyok, ${ }^{4}$ Imre Bodó ${ }^{5}$ \\ and Lajos Rózsa $\oplus^{6,7}$ \\ ${ }^{1}$ St. Raphael Ophthalmological Center, Mbuji Mayi, Democratic Republic of the Congo \\ ${ }^{2}$ Mátra Museum of the Hungarian Natural History Museum, Gyöngyös, Hungary \\ ${ }^{3}$ Bernhard Nocht Institute, Hamburg, Germany \\ ${ }^{4}$ Eberhard Karls University, Tübingen, Germany \\ ${ }^{5}$ Emory University School of Medicine, Atlanta, GA \\ ${ }^{6}$ MTA-ELTE-MTM Ecology Research Group, Pazmany Str. 1/C, Budapest 1117, Hungary \\ ${ }^{7}$ Evolutionary Systems Research Group, MTA Centre for Ecological Research, Tihany, Hungary
}

\begin{abstract}
African pythons (Pythonidae) and large vipers (Bitis spp.) act as definitive hosts for Armillifer armillatus and Armillifer grandis parasites (Crustacea: Pentastomida) in the Congo Basin. Since the proportion of snakes in bushmeat gradually increases, human pentastomiasis is an emerging zoonotic disease. To substantiate the significance of this threat, we surveyed snakes offered for human consumption at bushmeat markets in the Kole district, Democratic Republic of the Congo, for the presence of adult pentastomids. In Bitis vipers $(n=40)$, Armillifer spp. infestations exhibited an $87.5 \%$ prevalence and 6.0 median intensity. Parasite abundance covaried positively with viper length, but not with body mass. In pythons $(n=13)$, Armillifer spp. exhibited a $92.3 \%$ prevalence and 3.5 median intensity. The positive correlations between parasite abundance and python length or mass were statistically nonsignificant. Ninety-one percent of $A$. grandis were discovered in vipers and $97 \%$ of infected vipers hosted A. grandis, whereas $81 \%$ of A. armillatus specimens were found in pythons and $63 \%$ of infected pythons hosted A. armillatus. Thus, challenging the widespread notion of strict host specificity, we found 'reversed' infections and even a case of coinfection. In this study, we also gathered information about the snake consumption habits of different tribal cultures in the area. Infective parasite ova likely transmit to humans directly by consumption of uncooked meat, or indirectly through contaminated hands, kitchen tools or washing water.
\end{abstract}

Keywords: Armillifer spp., Zoonosis, Congo Basin, Bushmeat, Python spp., Bitis spp.

\section{INTRODUCTION}

Animals of rainforest ecosystems are heavily harvested. For rural populations in tropical regions, such as Subsaharan

Published online: October 13, 2017

Correspondence to: Lajos Rózsa, e-mail: lajos.rozsa@gmail.com
Africa, bushmeat is a major source of protein ( $\mathrm{Fa}$ et al. 2003), and also a vital source of financial income for households living in extreme poverty (de Merode et al. 2004). Hunting of wild animals is significantly increasing not only due to the continuous increase in the human population, but also as earlier impenetrable rainforests 


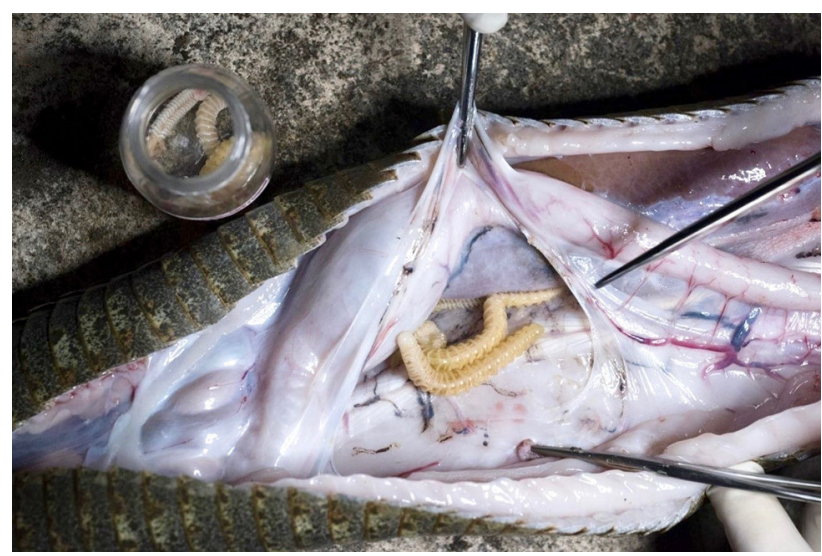

Figure 1. Armillifer grandis specimens found in the mesenteric folds of a 4-kg Rhinoceros Viper (Bitis nasicornis) at a bushmeat market. (Courtesy of András Hajdú D.)

become accessible through the expansion of roads related to extractive industries such as logging (Wilkie et al. 1992; Laurance et al. 2006) and mining (Edwards et al. 2014). When tackling the species composition of bushmeat, most studies focus on large-bodied mammals and birds. However, since overexploitation depleted populations of the more sought birds and mammals (Nasi et al. 2011), largebodied reptiles, such as snakes, monitors, crocodilians, turtles and tortoises, are also found in increasing numbers at bushmeat markets (Chifundera Kusamba et al. 2014).

Bushmeat, however, harbors the threat of spillover infections with pathogens that are novel and exotic to the human host (Karesh and Noble 2009). As a consequence, new zoonotic diseases are likely to emerge. Bats (Chiroptera), for instance, are important reservoirs of emerging viruses, including filoviruses (Changula et al. 2014), SARS coronavirus and others (Calisher et al. 2006). Recently, zoonotic parasites like Paragonimus westermani and Strongyloides fuelleborni have also caused emerging epidemics (Aka et al. 2008; Olsen et al. 2009). Among those infections, the reptile-borne pentastomiasis is an unusual and under-researched, neglected tropical disease in Africa, Asia and South America (Sulyok et al. 2014).

Pentastomids are parasitic crustaceans (Crustacea: Maxillopoda: Pentastomida) exhibiting a simplified vermiform body structure (Lavrov et al. 2004; Ruggiero et al. 2015) with annulations (ring-like thickening of the cuticle) resembling body segmentations. Armillifer grandis and $A$. armillatus have recently been identified as more widespread human pathogens in rural tropical Africa than previously thought. Their typical intermediate hosts are rodents and small-bodied primates, while they utilize snakes as defini- tive (final) hosts (Tappe et al. 2015). Specifically, adult $A$. armillatus are presumed to occur in the respiratory tracts of African pythons (e.g., Python sebae and P. regius), while adult $A$. grandis inhabits the lungs and tracheae of largebodied African 'puff adders' (e.g., Bitis gabonica and B. nasicornis) (Christoffersen and De Assis 2013). Unfortunately, host specificity data provided by early authors have limited values due to low sample sizes and the often unreliable identification of parasites. These snakes are among the most harvested reptile species sold for human consumption at Central and West African bushmeat markets (Chifundera Kusamba et al. 2014).

Human Armillifer infection is acquired by oral uptake of infective parasite ova in snake meat products (Magnino et al. 2009), or by contact via snake totemism (Dakubo et al. 2008). Though humans may harbor dozens or even hundreds of parasite larvae, clinical symptoms of abdominal infections are often lacking (Tappe and Büttner 2009). In contrast, the highly symptomatic ocular pentastomiasis (when parasites reside in or around the eye) cases are rare, representing only the tip of the iceberg of the disease burden (Sulyok et al. 2014). A recent observational study in the area identified $3.7 \%$ prevalence of asymptomatic abdominal pentastomiasis in patients undergoing abdominal surgery for various independent reasons (Tappe et al. 2016).

Here we investigate pentastomid infections of pythons and large-bodied Bitis spp. offered for sale at rural bushmeat markets in the Democratic Republic of the Congo (DRC). We aim to describe the distribution of parasites quantitatively, to analyze host specificity of the two Armillifer species and to investigate whether snake size predicts infection intensities. Finally, we also give a short summary of snake consumption habits and related beliefs in local tribes exposed to snake-borne pentastomid infections.

\section{Materials And Methods}

Large snakes were surveyed at the markets of Kole (Sankuru Province, $03^{\circ} 28^{\prime} 07^{\prime \prime} \mathrm{S}, 22^{\circ} 27^{\prime} 05^{\prime \prime} \mathrm{E}$ ) from April 2015 to February 2016. All snakes offered for sale originated from the vicinity $(<160 \mathrm{~km})$ of the town of Kole, except for a single python that was transported from Katanda, approx. $500 \mathrm{~km}$ away). Snake body length and mass were measured when possible, or at least estimated if the snake was already decapitated. Subsequently, snakes were dissected on the 
spot, and the respiratory organs (and their surrounding tissues) were inspected for adult pentastomids that are well visible to the naked eye (Fig. 1). Parasites were extracted using forceps and placed in $97 \%$ ethanol for subsequent morphological examination. Specimens with 19 annulations were identified as A. armillatus, and those with 26-28 (most often 26) annulations as A. grandis (Pantchev and Tappe 2011).

The survey at rural markets and the collecting of pentastomids were carried out by paid local helpers. The snake's taxonomic identification was based on local ethnic knowledge of animals. Snakes classified as 'vipers' most probably belonged to the genus Bitis, and represented $B$. gabonica and B. nasicornis, but B. arietans might have also been among the carcasses. Snakes identified as 'pythons' were most likely Python sebae, although a few specimens of $P$. regius might have also been present.

Following the standard terminology of ecological parasitology, sample 'prevalence' is the proportion of infected individuals within the whole sample, 'intensity' is the number of parasites in a host individual when the zero values of non-infected hosts are excluded, and 'abundance' is the number of parasites in a host individual when the zero values of non-infected hosts are included (Bush et al. 1997; Rózsa et al. 2000). Statistical analyses were carried out using Quantitative Parasitology on the Web (Reiczigel et al. 2013). Body length, body mass and infection abundance data were not transformed because all varied within a relatively narrow range (not across several magnitudes). The 95\% confidence intervals (CI) of prevalence were calculated applying Sterne's method (Reiczigel 2003).

Additionally, we also collected information on local habits and tribal beliefs about snake consumption from local people at the markets. We did not carry out formal interviews, rather we gathered anecdotal information given in response to our open-ended questions.

All snakes involved in our study were killed by local people for food. No animals were killed for our study purposes.

\section{Results}

\section{Vipers (Bitis spp.)}

A total of 40 vipers were surveyed during our study. Body length, body mass and infection abundance fell within the ranges of $0.3-1.6 \mathrm{~m}, 0.1-3.0 \mathrm{~kg}$ and $0-23$, respectively. Out of the 40 vipers examined, 35 carried adult Armillifer specimens (prevalence 0.875 , CI 0.739-0.949). The mean and median of infection intensity were 6.94 and 6.0, respectively, while the variance/mean ratio was 3.91 , indicating a moderate level of aggregation (Fig. 2).

Viper body length predicted the abundance of Armillifer infections significantly $\left(N=40, \quad R^{2}=0.290\right.$,

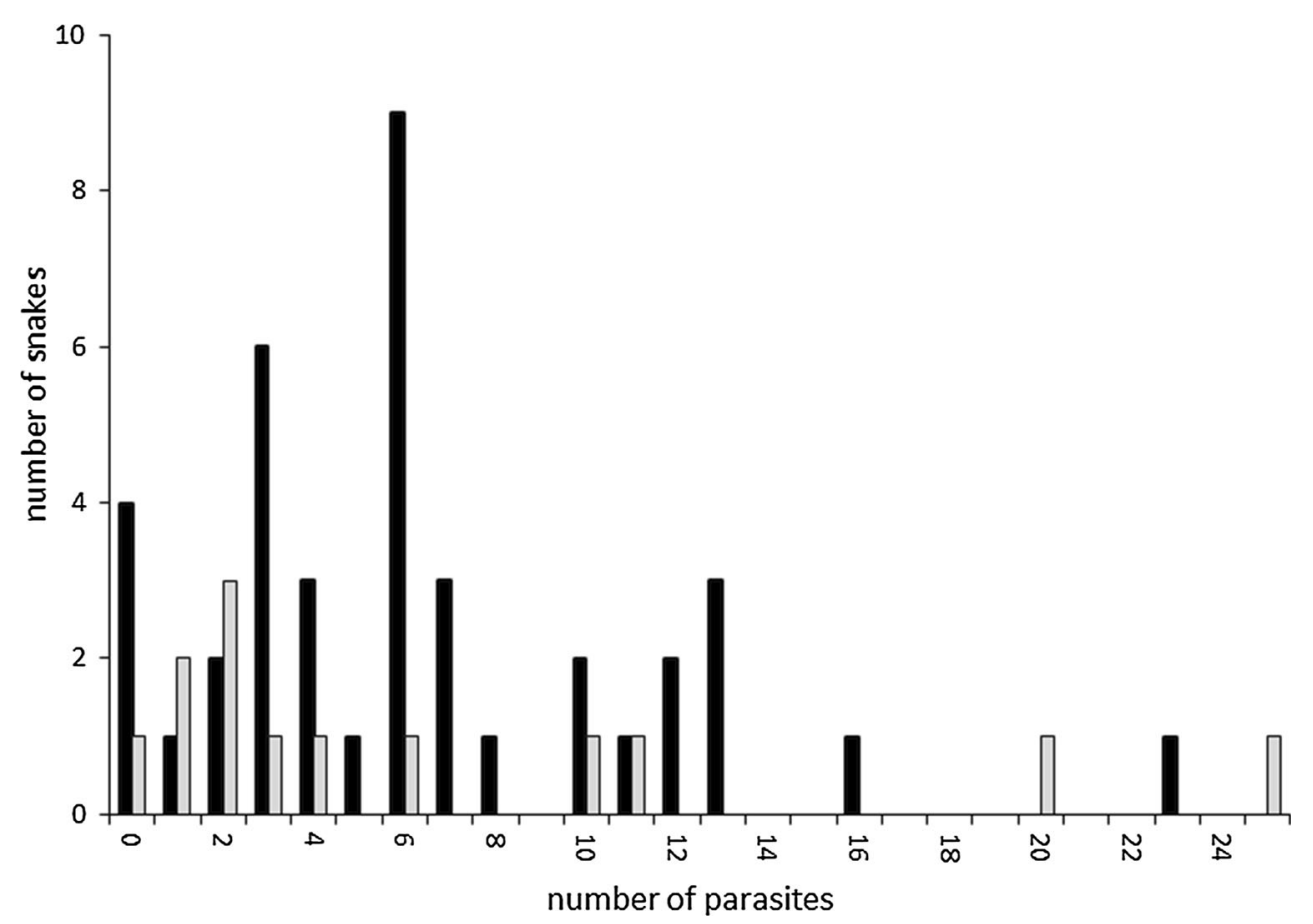

Figure 2. Frequency distributions of Bitis sp. vipers (dark bars) and Python sp. snakes (light bars) across parasite (both $A r$ millifer grandis and A. armillatus) infection categories 

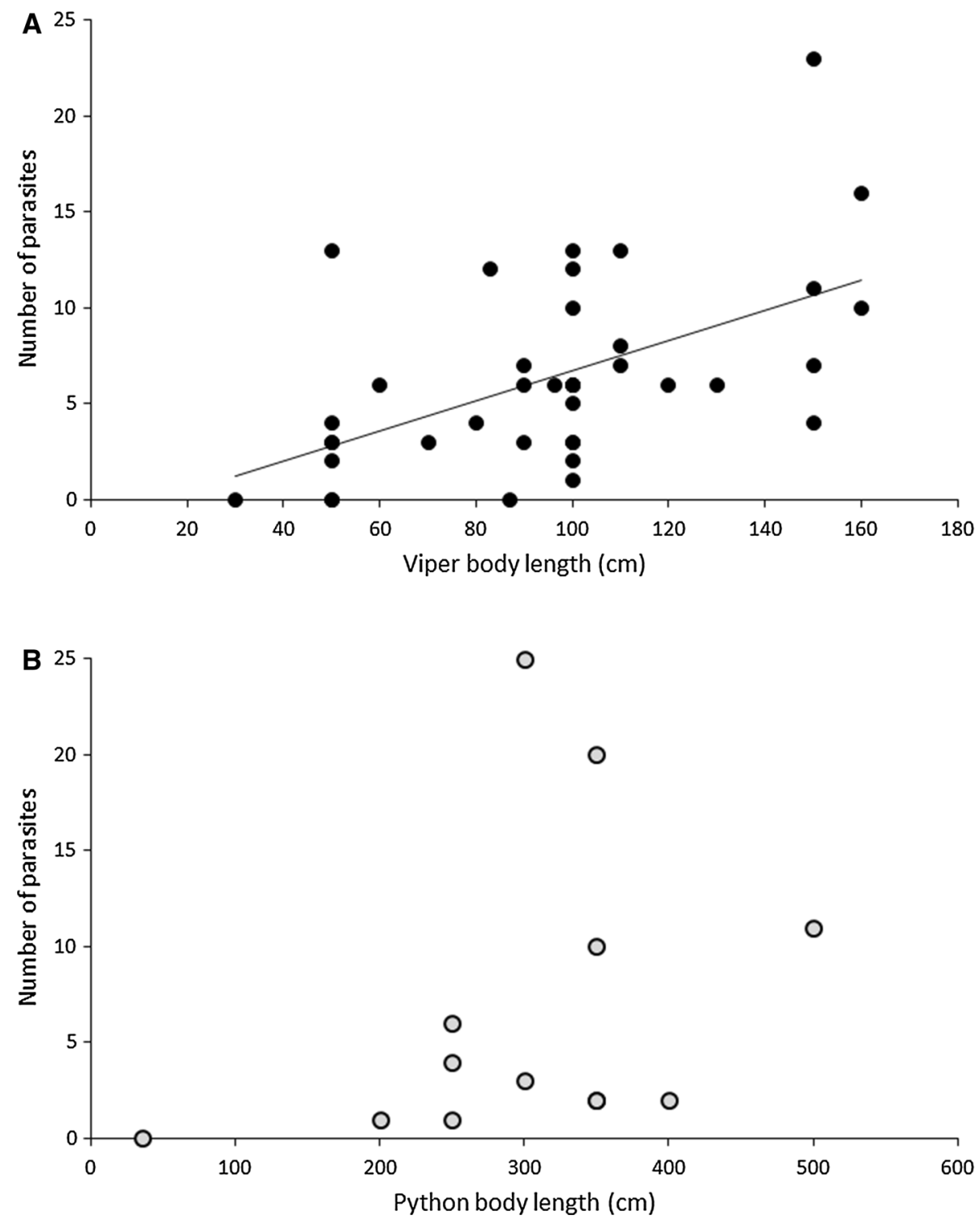

Figure 3. Relationship between snake body length and infection intensity. a The number of parasites (both Armillifer grandis and A. armillatus) in Bitis sp. vipers as a function of their body length (least square linear regression $N=40$, $Y=X \times 0.07832-1.092)$. b The number of parasites in pythons

$P<0.001)$ (Fig. 3a), while body mass $\operatorname{did}$ not $(N=39$, $\left.R^{2}=0.045, P=0.195\right)$.

$R^{2}=0.116, \quad P=0.256 ; \quad N=13, \quad R^{2}=0.101, \quad P=0.290$, respectively) (Fig. 3b).

Quantitative measures like prevalence, mean and

\section{Pythons}

A total of 13 pythons were examined during our study. Body length, body mass and infection abundance fell within the ranges of $0.35-5 \mathrm{~m}, 0.2-35 \mathrm{~kg}, 0-25$, respectively. Twelve of them carried adult Armillifer specimens (prevalence 0.923, CI 0.659-0.996). The mean and median of infection intensity were 7.25 and 3.5 , respectively, while the variance/mean ratio was 9.20 , indicating a moderate level of aggregation (Fig. 2).

There were no significant covariations between parasite abundance and python length or mass $(N=13$, median of intensity of viper versus python infections did not differ significantly (Fisher's exact test, $P=1.000$; Bootstrap 2-sample $t$ test, $P=0.899$; Mood's median test, $P=1.000)$.

\section{Host Specificity}

Out of the 258 A. grandis specimens collected, 235 were hosted by vipers and 23 by pythons. In contrast, out of the $64 \mathrm{~A}$. armillatus specimens, 12 were harbored by vipers and 52 by pythons. 
As expected, the majority of infected vipers (31 out of 33) hosted A. grandis. However, one of them had a coinfection with $A$. grandis and A. armillatus and another one harbored a sole $A$. armillatus only. Two samples were lost after measurements and parasite counting; thus, these parasites were not identified to species. Only five pythons hosted $A$. armillatus, while three of them harbored $A$. grandis. Coinfections did not occur in pythons. Four python samples were lost after measurements and parasite counting, and these parasites were not identified to species level.

\section{Tribal Knowledge}

Informal conversations with people selling or buying snakes at the markets revealed that snake consumption has various traditions in the region. We were told that the Baluba people in and around Mbuji Mayi, for instance, do not eat snakes, while for others, like the Songye people, snake meat is a prized commodity, though only for men. In this community, women do not eat snake meat, for it is believed to obliterate their fertility. Also, butchering and cooking snake meat are the exclusive tasks of males. They use traditional clay pots called 'luphukie' that are not used for any other types of food. Snakes are cooked for long periods. In other tribes, snake meat and internal organs are either fried in oily sauce or ember-roasted, usually between leaves, until they become soft. The washing water used to clean the kitchen pots and tools after snake butchery is often recycled; other pots and tools are washed subsequently in the same water. In addition, wastes of the butchered snakes are discarded behind the house and are usually consumed by livestock such as chicken or dogs.

Rural people in the area often seemed familiar with the body shape of pentastomids. Apparently, the spring-like annulations of these parasites make some of them to believe that these are mechanical springs of the snakes' body helping their movement. This belief may hinder the recognition of these parasites as a zoonotic threat.

\section{Discussion}

Knowledge of the herpetofauna of DRC is scarce. Taking the Gaboon viper and Rhinoceros viper as examples, they have been reported from the DRC only on two occasions in the literature (Schmidt 1923; Jackson et al. 2007), in spite of them being frequently found in all the surrounding countries. The scarcity of reports is probably due to the lack of focused surveys in this hard-to-access geographical region. As the DRC provides vast areas with suitable habitats for these species, our observations on the occurrence of these snake species are conceivably not unexpected.

Our sample sizes are admittedly small. However, in light of recurrent Congolese civil unrest, political instability and the extremely poor state of infrastructure, our results yield useful new information. These data indicate a surprisingly high prevalence of Armillifer spp. in both pythons and vipers. Thus, almost every single snake on the markets of Kole and its vicinity poses a zoonotic threat to consumers. For the first time, we provide statistical description of the frequency distribution of these parasites within the populations of their definitive hosts. Not surprisingly, these distributions are characteristically left-biased (aggregated) as it is often the case in macroparasites (Rózsa et al. 2000). There were no significant differences in the prevalence and intensity of infection in vipers versus pythons, although the statistical power of these comparisons was very weak due to the low sample size for pythons.

Contrary to suggestions by the current literature, $A$. armillatus is not entirely specific to pythons as final hosts, neither is A. grandis specific exclusively to vipers. A. grandis and $A$. armillatus parasitize both vipers and pythons, and even coinfections occur. However, our data show that $A$. grandis prefers vipers and most vipers indeed host $A$. grandis, whereas $A$. armillatus prefers to parasitize pythons and accordingly, most pythons host $A$. armillatus. Our identification of parasite species was based only on morphology (the number of ring-like annulations), a field method that a recent molecular study had confirmed (Tappe et al. 2016). To the best of our knowledge, host specificity of African Armillifer species has not been formerly tested using sample sizes comparable to ours.

Viper body length, but not weight, covaried positively with parasite abundance. Arguably, length is a rough surrogate indicator of a snake's age, while weight is a trait dependent more on a snake's actual nutrition state. Though the shape of this relationship appeared to be somewhat similar in pythons, this was not significant, probably due to their low sample size. Thus, these results suggest that the abundance of pentastomid infections likely increases with snakes' age (as indicated by the length).

These records are the first to quantify the zoonotic threat from pythons and large-bodied vipers of the genus Bitis sold for human consumption at rural markets of the DRC. Our results are disturbing and are in line with new 
data indicating an increasing number of human pentastomid infections in this area (Tappe et al. 2016). Consumption of snakes as bushmeat seems to be the general reason behind the emerging epidemics of human pentastomiasis. However, the precise way of parasite transmission is still not known. We suspect that infective eggs are likely transmitted to people (1) directly through eating uncooked snake meat, (2) through kitchen tools like pots and knives as fomites, (3) through recycling the water used to wash these tools (4) or by improper hand hygiene while handling snakes. Likely, a combination of these scenarios plays a role during human infection.

According to anecdotal information gathered through informal discussions, local people tend to cook meat intensively. Still, a hasty preparation of food, even if it occurs rarely, carries the risk of ingesting infective parasite ova. Transmission through kitchen tools cleaned in recycled washing water, or contaminated hands are likely alternatives. The specific gender-related food taboos of the Songye people, provided they are actually obeyed in practice, may offer the chance to deduce the route of infection by future gender-based prevalence studies. If infections are mostly transmitted through the food itself, then we expect infections to occur only in men. In contrast, if infections are mostly transmitted through recycled washing water, then we expect infections to show gender independence.

Furthermore, we do not know whether the discarded wastes of snake butchery consumed by dogs, chicken, pigs, etc., play an epidemiological role. Even if some of these animals may carry infective nymphs, they are unlikely to constitute a direct risk to human health because humans do not act as definitive hosts. However, synanthropic rodents may also feed on these wastes and then transmit infections to snakes attracted to human settlements to prey on them. This scenario predicts that snakes living in the spatial proximity of villages may become more infected than those living far from humans.

Briefly, our present findings point to a greatly underestimated public health relevance of the increasing interaction between the herpetofauna and rural people of equatorial Africa. The growth of human population size and the increasing consumption of snakes as bushmeat will predictably intensify the human-reptile interaction and the risk for spillover infections in the near future. There is a clear necessity of surveillance of parasite infections in bushmeat, and particularly in large-bodied vipers and pythons offered for human consumption to detect and prevent zoonotic diseases (Karesh and Noble 2009). In the short run, pictured brochures are needed to disseminate basic knowledge to local tribesmen about the role of snakes as sources of zoonotic threat and the necessary hygienic measures to avoid it. Further on, developing new ways to replace bushmeat as the main source of protein would yield benefits for human health and also decrease hunting pressure exerted on wildlife.

\section{ACKNOWLEDGEMENTS}

We thank András Hajdú D. for the photograph. The work of Lajos Rozsa was supported by grants from the National Scientific Research Fund of Hungary (OTKA/NKFI Grant No. 108571) and GINOP-2.3.2-15-2016-00057.

Compliance With Ethical Standards all procedures were in accordance with the 1964 Declaration of Helsinki and its later amendments or comparable ethical standards. More specifically, no reptile was killed for the purpose of the present study. All information about tribal knowledge and beliefs of local people were obtained though informal conversations with illiterate local people who gave their verbal consent to recite what they told us. Therefore, no ethics committee review was required.

CONFLICT OF INTEREST All the authors declare that they have no conflict of interest.

\section{REFERENCES}

Aka NA, Adoubryn K, Rondelaud D, Dreyfuss G (2008) Human paragonimiasis in Africa. Annals of African Medicine 7:153-162. doi:10.4103/1596-3519.55660

Bush AO, Lafferty KD, Lotz JM, Shostak AW, et al. (1997) Parasitology meets ecology on its own terms: Margolis et al. revisited. Journal of Parasitology 83:575-583. doi:10.2307/ 3284227

Calisher CH, Childs JE, Field HE, Holmes KV, Schountz T (2006) Bats: Important reservoir hosts of emerging viruses. Clinical Microbiology Reviews 19:531-545. doi:10.1128/CMR.00017-06

Changula K, Kajihara M, Mweene AS, Takada A (2014) Ebola and Marburg virus diseases in Africa: Increased risk of outbreaks in previously unaffected areas? Microbiology and Immunology 58:483-491. doi:10.1111/1348-0421.12181

Chifundera Kusamba Z, Nagy ZT, Kielgast J, Collet M, Mebert K, Gvozdik V (2014) Reptiles and amphibians as bushmeat in the Democratic Republic of the Congo. In: Abstracts Resumés. Anonymous (editor) 1st International Conference on Biodiversity in the Congo Basin, Centre de Surveillance de la Biodiversité, Kisangani, Democratic Republic of Congo, pp 186187

Christoffersen ML, De Assis JE (2013) A systematic monograph of the Recent Pentastomida, with a compilation of their host. Zoologische Mededelingen 87:1-206 
Dakubo J, Naaeder S, Kumodji R (2008) Totemism and the transmission of human pentastomiasis. Ghana Medical Journal 42:165-168

de Merode E, Homewood K, Cowlishaw G (2004) The value of bushmeat and other wild foods to rural households living in extreme poverty in Democratic Republic of Congo. Biological Conservation 118:573-581. doi:10.1016/j.biocon.2003.10.005

Edwards DP, Sloan S, Weng L, Dirks P, Sayer J, Laurance WF (2014) Mining and the African environment. Conservation Letters 7:302-311. doi:10.1111/conl.12076

Fa JE, Currie D, Meeuwig J (2003) Bushmeat and food security in the Congo Basin: linkages between wildlife and people's future. Environmental Conservation 30:71-78. doi:10.1017/ S0376892903000067

Jackson K, Zassi-Boulou A-G, Mavoungou L-B, Pangou S (2007) Amphibians and reptiles of the Lac Télé Community Reserve, Likouala Region, Republic of Congo (Brazzaville). Herpetological Conservation and Biology 2:75-86

Karesh WB, Noble E (2009) The bushmeat trade: increased opportunities for transmission of zoonotic disease. Mount Sinai Journal of Medicine 76:429-434. doi:10.1002/msj.20139

Laurance WF, Croes BM, Tchignoumba L, Lahm S, Alonso A, Lee ME, Campbell P, Ondzeano C (2006) Impacts of roads and hunting on Central African rainforest mammals. Conservation Biology 20:125-1261. doi:10.1111/j.1523-1739.2006.00420.x

Lavrov DV, Brown WM, Boore JL (2004) Phylogenetic position of the Pentastomida and (pan)crustacean relationships. Proceedings of the Royal Society B: Biological Sciences 271:537-544. doi:10.1098/rspb.2003.2631

Magnino S, Colin P, Dei-Cas E, Madsen M, McLauchlin J, Nöckler K, Maradona MP, Tsigarida E, Vanopdenbosch E, Van Peteghem C (2009) Biological risks associated with consumption of reptile products. International Journal of Food Microbiology 134:163-175. doi:10.1016/j.ijfoodmicro.2009.07.001

Nasi R, Taber A, Van Vliet I (2011) Empty forests, empty stomachs? Bushmeat and livelihoods in the Congo and Amazon Basins International Forestry Review 13:355-368. doi:10.1505/ 146554811798293872

Olsen A, van Lieshout L, Marti H, Polderman T, Polman K, Steinmann P, Stothard R, Thybo S, Verweij JJ, Magnussen P (2009) Strongyloidiasis - the most neglected of the neglected tropical diseases? Transactions of the Royal Society of Tropical Medicine and Hygiene 103:967-972. doi:10.1016/ j.trstmh.2009.02.013
Pantchev N, Tappe D (2011) Pentastomiasis and other parasitic zoonoses from reptiles and amphibians. Berliner und Münchener tierärztliche Wochenschrift 124:528-535

Reiczigel J, Rózsa L, Reiczigel A, Fábián I (2013) Quantitative Parasitology (QPweb). Available: http://www2.univet.hu/ qpweb/qp10/index.php [accessed January 11, 2017]

Reiczigel J (2003) Confidence intervals for the binomial parameter: some new considerations. Statistics in Medicine 22:611-621. doi:10.1002/sim.1320

Rózsa L, Reiczigel J, Majoros G (2000) Quantifying parasites in samples of hosts. Journal of Parasitology 86:228-232. doi:10.1645/0022-3395(2000)086[0228:QPISOH]2.0.CO;2

Ruggiero MA, Gordon DP, Orrell TM, Bailly N, Bourgoin T, Brusca RC, Cavalier-Smith T, Guiry MD, Kirk PM (2015) A higher level classification of all living organisms. PLoS ONE 10(4):e0119248. doi:10.1371/journal.pone.0119248

Schmidt KP (1923) Contributions to the herpetology of the Belgian Congo based on the collection of the American Museum Congo Expedition, 1909-1915. Part II. Snakes, with field notes by Herbert Lang and James P. Chapin. Bulletin of the American Museum of Natural History 49:1-146

Sulyok M, Rózsa L, Bodó I, Tappe D, Hardi R (2014) Ocular pentastomiasis in the Democratic Republic of the Congo. PLoS Neglected Tropical Diseases 8:e3041. doi:10.1371/journal.pntd.0003041

Tappe D, Büttner DW (2009) Diagnosis of human visceral pentastomiasis. PLoS Neglected Tropical Diseases 3(2):e320. doi:10.1371/journal.pntd.0000320

Tappe D, Sulyok M, Riu T, Rózsa L, Bodó I, Schoen C, Muntau B, Babocsay G, Hardi R (2016) Coinfections with Armillifer grandis, A. armillatus and Raillietiella sp. in visceral pentastomiasis, Democratic Republic of the Congo. Emerging Infectious Diseases 22:1333-1339. doi:10.3201/eid2208.151895

Tappe D, Sulyok M, Rózsa L, Muntau B, Haeupler A, Bodó I, Hardi R (2015) Molecular diagnosis of abdominal Armillifer grandis pentastomiasis in the Democratic Republic of Congo. Journal of Clinical Microbiology 53:2362-2364. doi:10.1128/ JCM.00336-15

Wilkie DS, Sidle JG, Boundzanga GC (1992) Mechanized logging, market hunting, and a bank loan in Congo. Conservation Biology 6:570-580. doi:10.1046/j.1523-1739.1992.06040570.x 